\title{
Modification of titanium phosphate precipitated from titanylsulfate
}

\author{
W. Janusz ${ }^{1} \cdot$ S. Khalameida ${ }^{2}$ E. Skwarek ${ }^{1} \cdot$ J. Skubiszewska-Zięba ${ }^{1} \cdot$ V. Sydorchuk ${ }^{2} \cdot$ B. Charmas ${ }^{1}$
}

Received: 23 February 2018/Accepted: 29 July 2018/Published online: 16 August 2018

(C) The Author(s) 2018

\begin{abstract}
The titanium phosphate-synthesized sol-gel method was subjected to the mechanochemical treatment in a planetary ball mill Pulverisette 6 in air or water environment or the hydrothermal treatment at $873 \mathrm{~K}$ or $1073 \mathrm{~K}$. The properties of such modified/treated samples were examined using the XRF, XRD, TGA, static light scattering, FTIR Raman and adsorption/ desorption of $\mathrm{N}_{2}$ methods. The mechanochemical treatment of xerogel samples leads to a small decrease in water contents in the sample, but the structure remains amorphous. Additionally, during milling of the sample aggregation of titanium phosphate particles and a decrease in specific surface area were observed. The hydrothermal treatment of the xerogel sample leads to a crystal product composed of titanium oxide phosphate hydrate, titanium oxide phosphate and titanium dioxide. The TGA analysis confirms the presence of titanium oxide phosphate hydrate. The hydrothermally treated titanium phosphate samples are monodispersed and have a larger specific surface area than the initial sample.
\end{abstract}

Keywords Titanium phosphate $\cdot$ Mechanochemical treatments $\cdot$ Thermogravimetric analysis

\section{Introduction}

Titanium phosphates (TiP) of different compositions are effective ion-exchangers, acid-oxidizers, photocatalysts, solid electrolytes [1-6]. Their properties are determined by the $\mathrm{Ti} / \mathrm{P}$ ratio, crystal and porous structure, morphology and ultimately the synthesis method. By varying the synthesis conditions of TiP, it is possible to control their main physicochemical properties: specific surface area, crystal and porous structure, and surface acidity. First of all, amorphous and crystalline titanium hydrophosphates $\mathrm{Ti}\left(\mathrm{HPO}_{4}\right)_{2}$ have important applications [1-3]. The review of TiP preparation methods is presented in papers $[1,7,8]$. Among them, the sol-gel and template syntheses allow to prepare mesoporous and hierarchically organized mesomacroporous TiP [4, 5, 9-12]. There were prepared titanium phosphates of different compositions and porous

W. Janusz

wjanusz@hermes.umcs.lublin.pl

$\triangle$ E. Skwarek

ewunias@hektor.umcs.lublin.pl

Maria Curie-Skłodowska University, Lublin, Poland

2 Institute for Sorption and Problems of Endoecology, NAS of Ukraine, Naumov Str. 13, Kyiv 03164, Ukraine structures: the specific surface area up to $740 \mathrm{~m}^{2} \mathrm{~g}^{-1}$ and the pore volume up to $1 \mathrm{~cm}^{3} \mathrm{~g}^{-1}$. However, the mesopore diameters are as a rule only within $2-5 \mathrm{~nm}$. Moreover, the above-mentioned procedures are fairly complex and require the use of expensive reagents as well as the additional calcinations for templates removal.

The characteristics can be also varied during further treatment of as-prepared phosphates, i.e., during modification of the sample structure. For example, hydrothermal (HTT) and mechanochemical (MChT) techniques are effective methods which allow to modify phosphates of different structures and adsorption properties [13, 14]. However, there are only few papers [15-17] which deal with modification of titanium phosphate structure using HTT. Thus, the authors of $[16,17]$ studied the HTT of TiP at low temperatures- 130 and $160{ }^{\circ} \mathrm{C}$. It should be noted that only dried xerogels were investigated, although modification in the stage of wet gel enhances the control of the porous structure parameters $[14,15]$. MChT of TiP was not investigated earlier.

The authors of [16-18] also proposed the use of titanium oxysulfate as a source of titanium instead of more expensive titanium chloride and alcoholates. HTT of the TiP xerogel prepared from $\mathrm{TiOSO}_{4}$ leads to the formation of the samples with the pore volume $0.5-1.15 \mathrm{~cm}^{3} \mathrm{~g}^{-1}$ and the pore size $10-22 \mathrm{~nm}$ which were used as ion- 
exchangers. However, the possibilities of crystal and porous structure variation have not been studied so far.

The study of regularities and peculiarities of hydrothermal and mechanochemical modification of titanium hydrophosphate wet gel and dried xerogel precipitated from titanylsulfate is the aim of this paper. Porous and crystal structure of TiP, modified under different conditions, was investigated in detail.

\section{Experimental}

\section{Materials}

\section{Synthesis of titanium phosphate}

Titanium phosphate (TiP) with the ratio $\mathrm{Ti} / \mathrm{P}=1$ was synthesized in the form of gelatinous precipitate (called "gel"). The procedure of preparation was as follows:

- $26.4 \mathrm{~g}$ of $\left(\mathrm{NH}_{4}\right)_{2} \mathrm{HPO}_{4}$ was dissolved in $200 \mathrm{~mL}$ of water;

- the obtained solution was added dropwise to $100 \mathrm{~mL}$ of $2 \mathrm{M}$ aqueous solution of $\mathrm{TiOSO}_{4}$ with vigorous stirring for $30 \mathrm{~min}$;

- the precipitate was aged in the mother liquor for $60 \mathrm{~min}$;

- then the precipitate was washed with water (the total amount c.a. 35 L) through decantation;

- the precipitate was subjected to filtration and compaction;

- the part of precipitate was dried at room temperature for $72 \mathrm{~h}$ (called "xerogel").

TiP was subjected to hydrothermal and mechanochemical treatments (HTT and MChT, respectively) in the form of wet gel and dried xerogel.

Mechanochemical treatment (MChT) was performed out in a planetary ball mill Pulverisette 6 (Fritsch) at the rotation speed of $600 \mathrm{rpm}$ in air (dry milling) and water (wet milling). The samples subjected to the mechanical treatment were designated "MChT-air" and "MChT-water", respectively. Ten tungsten carbide balls of $15 \mathrm{~mm}$ diameter (total mass-130 g) as well as the tungsten carbide vessel $(250 \mathrm{~mL})$ were used. The amount of milled TiP was equal to $10 \mathrm{~g}$. Thus, the mass balls-to-TiP (BPR) ratio was $13: 1$. The time of treatment was $2 \mathrm{~h}$. The volume of water added into the mill for wet milling was $80 \mathrm{~mL}$. The hydrothermal treatment (HTT) in the form of wet gel and dried xerogel was carried out in a stainless steel autoclave of $45 \mathrm{~mL}$ volume at 200 and $300{ }^{\circ} \mathrm{C}$ and under the autogeneous pressure for $5 \mathrm{~h}$. (The samples were designated "HTT-xero-200" and "HTT-xero-300", respectively). The reaction mixture contained $5 \mathrm{~g}$ of $\mathrm{TiP}$ and $10 \mathrm{~mL}$ of water when the xerogel was treated. In both cases, the wet gel and dried xerogel were charged in a quartz tube placed in the autoclave. However, $10 \mathrm{~mL}$ of water was added to the bottom of the autoclave when the xerogel was treated for HTT to be performed in the vapor phase. The obtained products were dried at $80{ }^{\circ} \mathrm{C}$ for $48 \mathrm{~h}$ after MChT and HTT.

The porous structure of TiP samples was studied using the adsorption-structural methods. Nitrogen adsorptiondesorption isotherms were obtained using an automatic gas adsorption analyzer ASAP $2405 \mathrm{~N}$ ("Micromeritics Instrument Corp") after outgassing of the samples at $150{ }^{\circ} \mathrm{C}$ for $2 \mathrm{~h}$. The specific surface area $S$ and the volume of mesopores $V_{\text {me }}$ were calculated from these isotherms using the BET and BJH methods, respectively. The sorption pore volume $V_{\mathrm{s}}$ was determined at a relative pressure of nitrogen $p / p_{0}$ close to 1 . The total pore volume $V_{\Sigma}$ was determined by means of impregnation of the samples dried at $150{ }^{\circ} \mathrm{C}$ with liquid water. The volume of macropores $V_{\text {ma }}$ was calculated as the difference between $V_{\Sigma}$ and $V_{\mathrm{s}}$. The curves of pore size distribution (PSD) were plotted using the desorption branches of isotherms.

The initial TiP and products of its modification were studied by means of X-ray powder diffraction (XRD, Empyrean) using the Philips PW 1830 diffractometer with $\mathrm{CuK}_{\alpha}$ radiation. The curves of DTA and TG were recorded using the Derivatograph-C apparatus (F. Paulik, J. Paulik, L. Erdey) in the temperature range $20-800{ }^{\circ} \mathrm{C}$ at the heating rate $10^{\circ} \mathrm{min}^{-1}$ in air atmosphere. The initial mass of the sample was about $25 \mathrm{mg}$. The FTIR spectra in the range $4000-400 \mathrm{~cm}^{-1}$ were registered using the "Spectrum-One" spectrometer (Perkin-Elmer). The ratio of the sample to the $\mathrm{KBr}$ powder was 1:20. The Raman spectra were collected using a micro-Raman spectroscopy system (inVia-Reflex, Renishaw, Co., UK). The content of Ti and $\mathrm{P}$ in the initial sample was determined using the $\mathrm{X}$-ray fluorescent analysis XRF (Axios mAX PANalytical). The particle size distributions were determined by means of the Mastertasizer 2000 apparatus produced by Malvern.

\section{Results and discussion}

The results of the XRF analysis of the samples are presented in Table 1. As can be seen besides Ti and P, other elements are present in the samples as impurities. Most of them are present as trace elements, but the content of $\mathrm{Fe}$ may be the result of its presence in titanium oxide sulfate [18] and higher contents are found in the samples after the HTT in the steel autoclave using a quartz tube after the MChT treatment. W and Co in the samples come from the ball mill material. The presence of sulfur in the "initial" and MChT-air samples indicates that part of titanium 
Table 1 The results of XRF analysis of titanium phosphate samples

\begin{tabular}{|c|c|c|c|c|c|c|}
\hline \multirow[t]{2}{*}{ Element } & \multicolumn{6}{|c|}{ Concentration/ \% } \\
\hline & Initial & MChT-air & MChT-water & HTT-gel-200 & HTT-xero-200 & HTT-xero-300 \\
\hline $\mathrm{P}$ & 10.70 & 10.67 & 17.52 & 19.36 & 14.48 & 15.60 \\
\hline $\mathrm{S}$ & 1.45 & 1.45 & 0.00 & 0.04 & 0.02 & 0.30 \\
\hline $\mathrm{Ti}$ & 25.70 & 25.40 & 33.11 & 31.48 & 28.77 & 26.50 \\
\hline $\mathrm{Fe}$ & 0.20 & 0.20 & 0.34 & 1.72 & 1.63 & 1.72 \\
\hline Co & & 1.35 & 2.34 & & & \\
\hline $\mathrm{W}$ & & 0.55 & 0.34 & & & \\
\hline Sum & 38.21 & 39.83 & 54.08 & 53.45 & 45.09 & 44.25 \\
\hline $\mathrm{Ti}+\mathrm{P}$ & 36.40 & 36.07 & 50.63 & 50.84 & 43.25 & 42.10 \\
\hline Impurities $=\mathrm{Al}, \mathrm{Si}, \mathrm{K}, \mathrm{Ca}, \mathrm{Zr}, \mathrm{Nb}$ & 1.81 & 3.76 & 3.45 & 2.61 & 1.84 & 2.15 \\
\hline $\mathrm{Ti} / \mathrm{P}$ & 2.402 & 2.38 & 1.89 & 1.63 & 1.99 & 1.70 \\
\hline
\end{tabular}

oxysulfate did not react completely with diammonium hydrogen phosphate. The amount of sulfur in the other samples is lower because titanium oxysulfate was washed out with water during the MChT and HTT. The Ti/P ratio of the "initial" sample is higher than for $\mathrm{Ti}_{2} \mathrm{O}_{3}\left(\mathrm{H}_{2} \mathrm{PO}_{4}\right)_{2}$ $* 2 \mathrm{H}_{2} \mathrm{O}$ which was probably formed during the reaction of diammonium hydrogen phosphate with titanium oxysulfate.

The XRD patterns of initial, MChT-air and MChT-water samples are depicted in Fig. 1. As can be seen from Fig. 1, the XRD pattern for the "initial" sample indicates that it is amorphous, whereas in the pattern of MChT-air sample, four small peaks characteristic of the tungsten carbide structure can be seen, PDF card No. 04-007-5192. Their presence in the sample results from milling of the sample

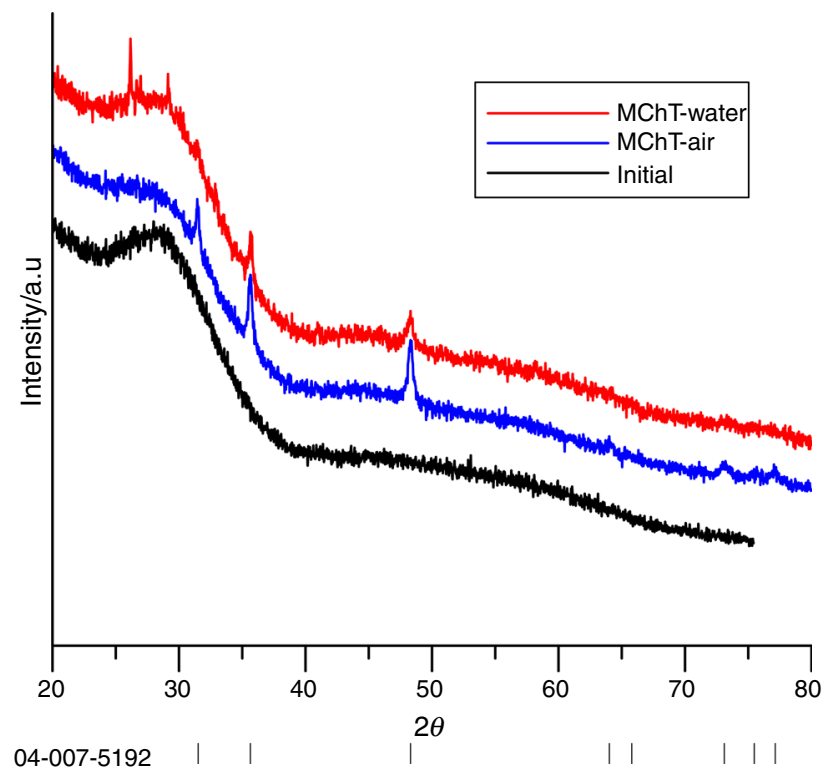

Fig. 1 The XRD patterns of titanium phosphates: the initial, MChTair and MChT-water treated samples using the tungsten carbide balls. The same peaks can be observed for the samples subjected to the mechanochemical treatment in water (Fig. 1, MChT-water plot), with the additional two small peaks at $2 \theta=26.19$ and $29.14^{\circ}$ which may indicate the presence of titanium oxide phosphate hydrate $\left(\mathrm{Ti}_{2}\left(\mathrm{PO}_{4}\right)_{2} \mathrm{O}\left(\mathrm{H}_{2} \mathrm{O}\right)\right.$, PDF card 04-014-9177 as in [18]. The latter indicates crystallization of some amorphous TiP under these conditions.

The XRD patterns of HTT-gel-200, HTT-xero-200 and HTT-xero-300 are depicted in Fig. 2. The peaks of the XRD patterns indicate the presence of titanium oxide phosphate hydrate (PDF card 04-014-9177) and titanium oxide phosphate $\left(\mathrm{Ti}_{5}\left(\mathrm{PO}_{4}\right)_{4} \mathrm{O}_{4}\right.$ (PDF card 04-012-4791) as well as $\mathrm{TiO}_{2}$ anatase (PDF card 04-002-8296). Additionally, in the HTT-gel-200 and HTT-xero-200 samples the
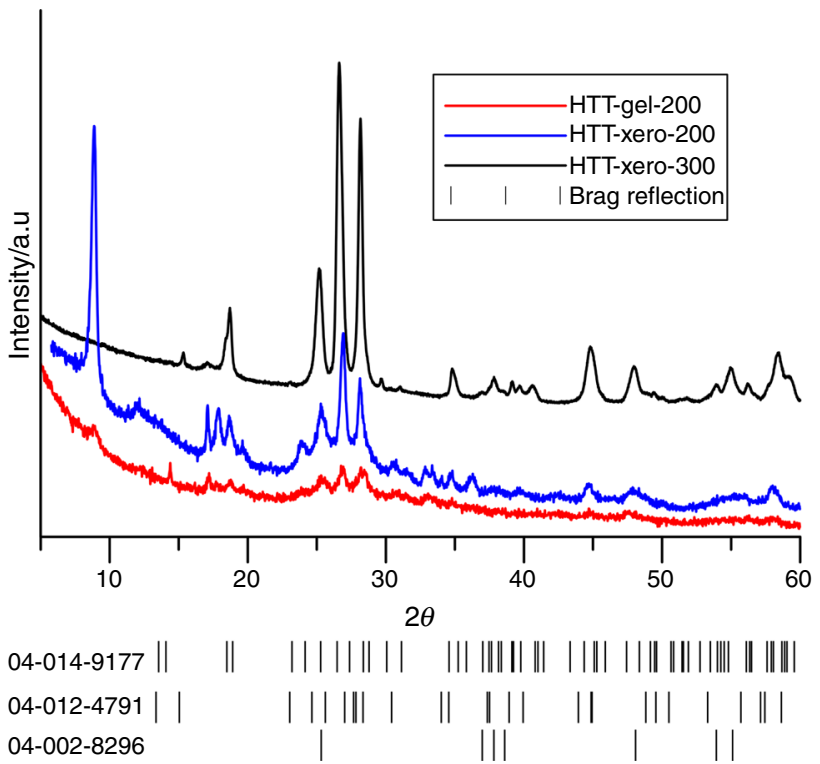

Fig. 2 The XRD patterns of the titanium phosphates samples: HTTgel-200, HTT-xero-200 and HTT-xero-300 
Table 2 The mass percentages of phases in the samples

\begin{tabular}{lllll}
\hline Phase name & PDF card no. & Sample & \\
\cline { 3 - 5 } & & $\begin{array}{l}\text { HTT-gel-200 } \\
(\% \mathrm{w} / \mathrm{w})\end{array}$ & $\begin{array}{l}\text { HTT-xero-200 } \\
(\% \mathrm{w} / \mathrm{w})\end{array}$ & $\begin{array}{l}\text { HTT-xero-300 } \\
(\% \mathrm{w} / \mathrm{w})\end{array}$ \\
\hline $\mathrm{TiO}_{2}$ (anatase) & & 19 & 16 & 67 \\
Titanium oxide phosphate hydrate $\left(\mathrm{Ti}_{2}\left(\mathrm{PO}_{4}\right)_{2} \mathrm{O}\left(\mathrm{H}_{2} \mathrm{O}\right)\right)$ & $04-014-9177$ & 67 & 12 & 67 \\
Titanium oxide phosphate $\left(\mathrm{Ti}_{5}\left(\mathrm{PO}_{4}\right)_{4} \mathrm{O}_{4}\right)$ & $04-012-4791$ & 14 & 17 & 21 \\
\hline
\end{tabular}

peak at $2 \theta=8.7$ indicates the presence of layered titanium phosphate, $\mathrm{Ti}_{2} \mathrm{O}_{3}\left(\mathrm{H}_{2} \mathrm{PO}_{4}\right)_{2} \cdot 2 \mathrm{H}_{2} \mathrm{O}$ [17]. Table 2 presents the results of the Rietveld refinement method using the Empyrean PANalytical software and the database of the samples of HTT-gel-200, HTT-xero-200 and HTT-xero300. As can be seen, the amount of $\mathrm{TiO}_{2}$ anatase structure is larger for the gel sample hydrothermally treated at $200{ }^{\circ} \mathrm{C}$ and it is lowest for the xerogel sample hydrothermally treated at $300{ }^{\circ} \mathrm{C}$, whereas in the case of titanium oxide phosphate it is contrary. It is obvious that part of anatase was transformed into titanium oxide phosphate in the latter case. The crystallite dimensions determined with the Scherrer's method from the half width of the peak for the angle $2 \theta=26.77^{\circ}$ for titanium oxide phosphate were $23.6 \mathrm{~nm}, 22.1 \mathrm{~nm}$ and 21.5 for HTT-gel-200, HTT-xero200 and HTT-xero-300, respectively. For titanium oxide phosphate hydrate, the angle $2 \theta=26.77^{\circ}$ was $16.8 \mathrm{~nm}$, $14.7 \mathrm{~nm}$ and $15.5 \mathrm{~nm}$ for HTT-gel-200, HTT-xero-200 and HTT-xero-300, respectively.

The thermogravimetric curves (TG, DTG and DTA) of the titanium phosphate samples: initial, MChT-air, HTT-gel200, HTT-xero-200 and HTT-xero-300 registered in the temperature range $25-800{ }^{\circ} \mathrm{C}$, are depicted in Figs. $3-7$,

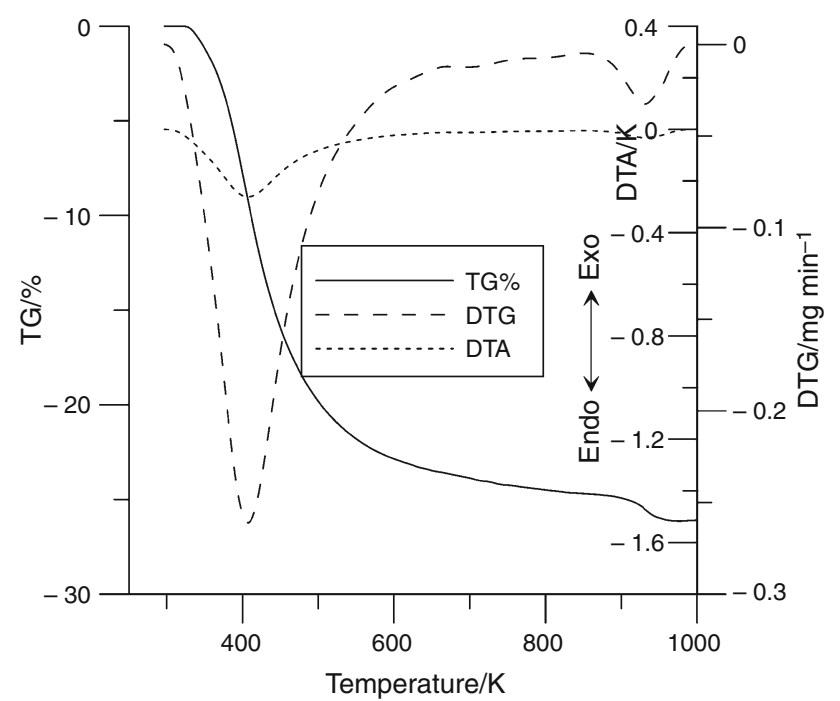

Fig. 3 The TG, DTG and DTA curves of the initial titanium phosphate sample respectively. Primarily, it should be noted that there are some general patterns and features of the processes resulting in the mass loss:

1. The mass loss observed up to $473 \mathrm{~K}$ is mainly associated with removal of physically adsorbed water and depends, first of all, on porous structure. The maximum contribution of this component is obtained for the initial and milled samples (Figs. 3, 4).

2. The release of crystallization water and structurebound water takes place at 473-773 K. The content of this type of water increases after HTT (Figs. 5-7). The latter is associated with formation of titanium phosphate hydrate phases under these conditions as shown by the XRD data.

3. The minimum contribution to the mass loss is made by the removal of sulfur impurity in the forms of oxides which is observed at $923-1023 \mathrm{~K}$. This is consistent with the literature on decomposition of titanylsulfate $[19,20]$. As can be seen, the release of sulfur is accompanied by the exoeffect in the same temperature range (Figs. 3-6). Its intensity and the corresponding mass loss decrease with the decreasing sulfur impurity

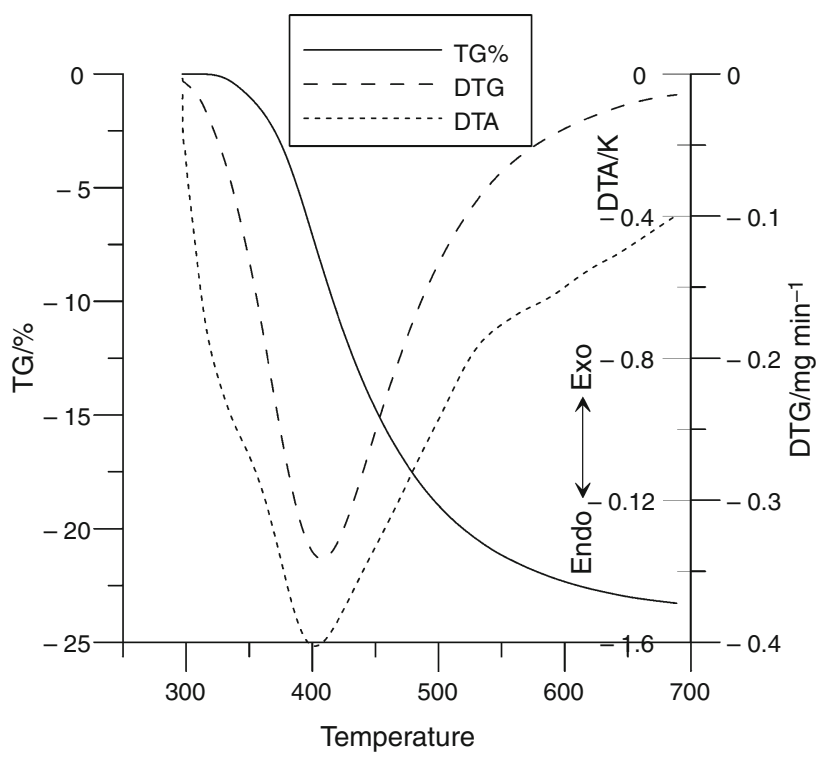

Fig. 4 The TG, DTG and DTA curves of the MChT-air sample 


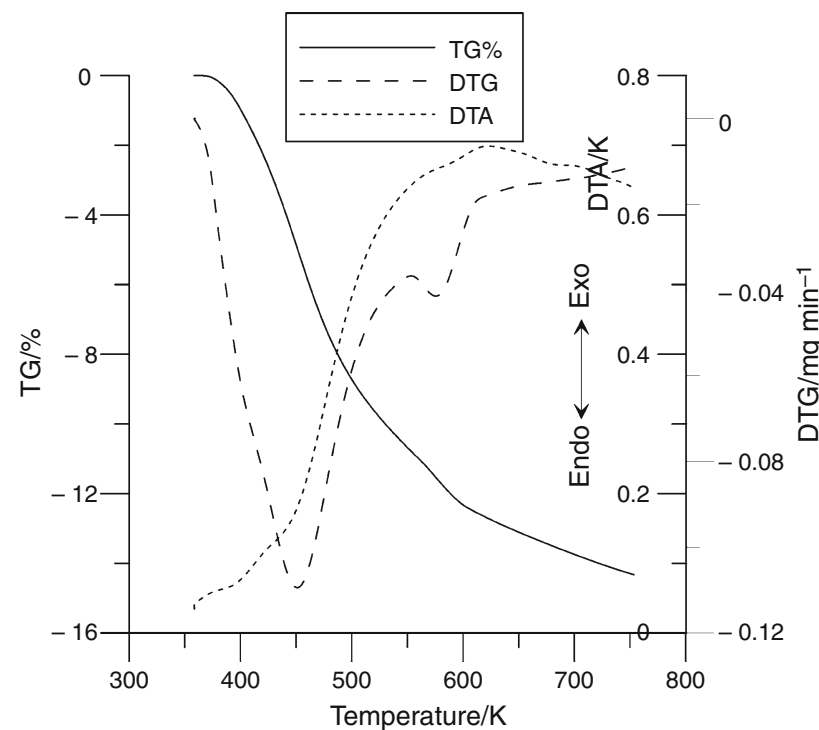

Fig. 5 The TG, DTG and DTA curves of the HTT-gel-200 sample

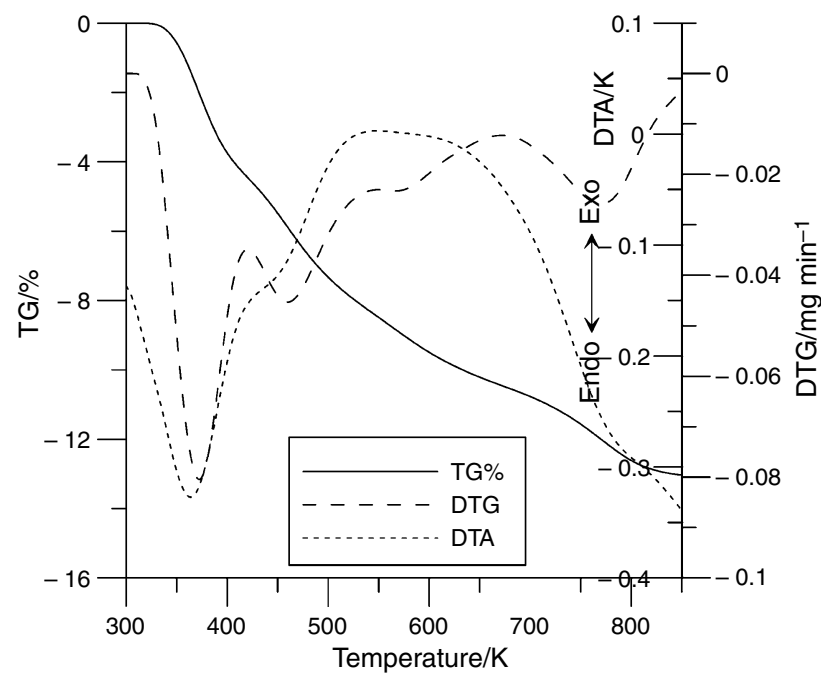

Fig. 6 The TG, DTG and DTA curves of the HTT-xero-200 sample

content in accordance with the XRF data (Table 1). Particularly, this concerns the hydrothermal samples compared with the initial and milled in air samples.

Moreover, the DTA-TG results for all samples are considered in more detail. As can be seen on the TG curve of the initial sample in Fig. 3, the total mass loss from the sample up to $1073 \mathrm{~K}$ was $26.1 \%$. The DTG curve of this sample demonstrates three main stages of mass loss: sharp at $298-663 \mathrm{~K}$ and $863-990 \mathrm{~K}$ as well as not sharp monotonic at $663-863 \mathrm{~K}$. The thermogravimetric analysis of the titanium phosphate $\mathrm{Ti}_{2} \mathrm{O}_{3}\left(\mathrm{H}_{2} \mathrm{PO}_{4}\right)_{2} \cdot 2 \mathrm{H}_{2} \mathrm{O}$ samples shows [21-24] that the decomposition occurs in three steps with the total mass loss $19.3 \%$ due to release of 4 water molecules ( 2 molecules of crystallization water and 2 molecules

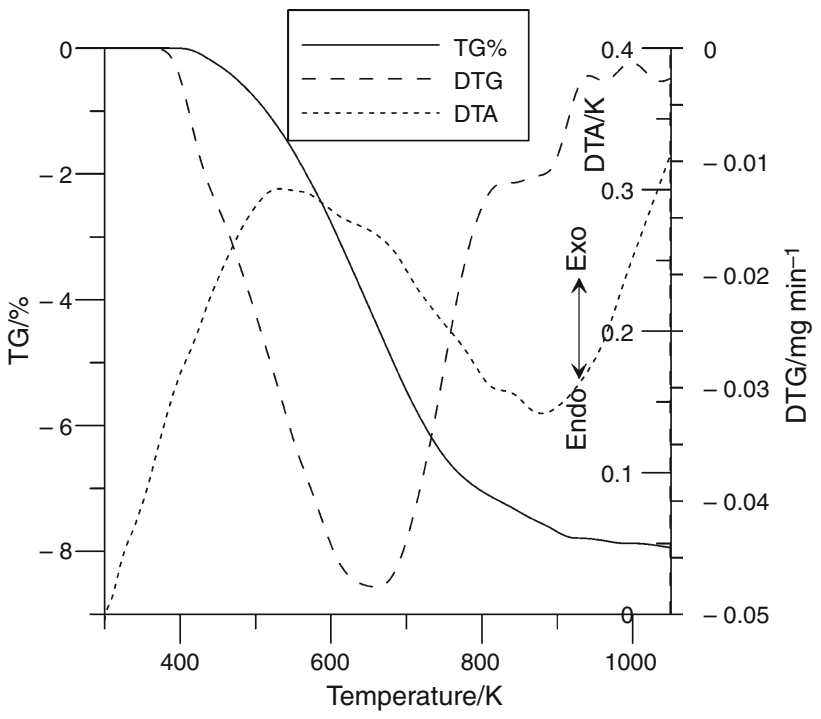

Fig. 7 The TG, DTG and DTA curves of the HTT-xero-300 sample

of structurally bound one). On the other hand, Maslova et al. [25] synthesized the titanium phosphate samples in the $\mathrm{TiO}_{2}-\mathrm{H}_{2} \mathrm{SO}_{4}-\mathrm{H}_{3} \mathrm{PO}_{4}-\mathrm{H}_{2} \mathrm{O}$ system using different concentrations of $\mathrm{TiO}_{2}$ and $\mathrm{H}_{2} \mathrm{SO}_{4}$, and the TG analysis of these samples shows that the total mass loss ranged from 25.11 to $29.25 \%$ as a result of decomposition of titanium phosphate samples composed of $\mathrm{Ti}(\mathrm{OH})_{2}(-$ $\left.\mathrm{HPO}_{4}\right) \cdot 0.86 \mathrm{H}_{2} \mathrm{O}$ and $\mathrm{Ti}\left(\mathrm{HPO}_{4}\right)_{2} \cdot \mathrm{H}_{2} \mathrm{O}$. They found a larger mass loss for the samples containing $\mathrm{Ti}(\mathrm{OH})_{4}$ with $33 \%$ $\mathrm{H}_{2} \mathrm{O}$ [26]. In our case, the presence of this compound is confirmed by a larger titanium content in the initial sample (Table 1). It is possible that all indicated phases are present in the initial sample in the amorphous state. A larger mass loss observed by us for the initial sample (the TG curve in Fig. 3) may result from this. Besides, removal of $1.45 \%$ of sulfur also contributes to the overall mass loss; the XRF analysis shows that at $773 \mathrm{~K}$ its concentration increases as a result of water desorption to $1.81 \%$ and further with the temperature increase up to $1023 \mathrm{~K}$ its concentration decreases by $0.62 \%$ as a result of sulfate compounds decomposition (Table 3). The DTA curve shows a peak at $993 \mathrm{~K}$ (as in [18]) which can result from the exothermic structural changes in $\mathrm{TiP}$ as is confirmed by comparison of XRD patterns for the initial samples heated at $773 \mathrm{~K}$ and $1023 \mathrm{~K}$, the first one is amorphous, whereas the second one is crystalline composed of titanium dioxide (rutile-PDF 004-014-7819 and anatase PDF 04-002-8296 structure) and titanium phosphate $\left(\mathrm{Ti}_{4} \mathrm{P}_{6} \mathrm{O}_{23}\right)$, PDF 00-039-0004, Fig. 8.

The results of thermal decomposition of the titanium phosphate sample after the mechanochemical process in air are depicted in Fig. 4. As can be seen, the obtained curves are similar to those registered for the initial sample; however, the first stage of mass loss is in the wide temperature range 303-824 K. As follows from the TG curve, the total 
Table 3 The results of XRF analysis of the initial titanium phosphate samples heated at temperatures $773 \mathrm{~K}$ and $1023 \mathrm{~K}$

\begin{tabular}{lrrr}
\hline Element & \multicolumn{3}{c}{ Heating temp./K } \\
\cline { 2 - 4 } & \multicolumn{2}{c}{293} & \multicolumn{1}{c}{} \\
\hline $\mathrm{P}$ & $\mathbf{1 0 . 7 0}$ & $\mathbf{1 3 . 9 0}$ & $\mathbf{1 3 . 2 0}$ \\
$\mathrm{S}$ & 1.45 & 1.81 & 0.62 \\
$\mathrm{Ti}$ & $\mathbf{2 5 . 7 0}$ & $\mathbf{3 4 . 7 0}$ & $\mathbf{3 6 . 3 0}$ \\
$\mathrm{Fe}$ & 0.20 & 0.28 & 0.34 \\
$\mathrm{Sum}$ & 38.21 & 50,91 & 50.91 \\
$\mathrm{Ti}+\mathrm{P}$ & 36.40 & 48.60 & 49.50 \\
Impurities = Al, Si, K, Ca, Zr, Nb & 1.81 & 2.31 & 1.41 \\
Ti/P & 2.402 & 2.50 & 2.75 \\
\hline
\end{tabular}

mass loss is $24.20 \%$. The mass loss larger than $23.9 \%$ may indicate the presence of titanium hydroxide in the sample and release sulfur at a temperature higher than $873 \mathrm{~K}$ which is consistent with the XRF analysis (Table 1). The peak on the DTA curve at $993 \mathrm{~K}$ can be attributed to the exothermic structural changes in TiP.

The curves of TGA analysis for the sample subjected to the hydrothermal treatment in the form of gel at $473 \mathrm{~K}$ (HTT-gel-200) can be seen in Fig. 5. The total mass loss calculated from the TG curve is $15.3 \%$ which is larger than for the compound found in the XRD pattern, namely $\mathrm{Ti}_{2}\left(\mathrm{PO}_{4}\right)_{2} \mathrm{O} \cdot \mathrm{H}_{2} \mathrm{O}$ (the calculated water content-5.63\%). As the XRD pattern of this sample shows small peaks, a large fraction of amorphous phase of titanium phosphate is probably retained in this sample which may cause a larger mass loss during the thermal decomposition. The DTG curve of this sample shows the presence of three peaks with the maxima about 451,575 and $935 \mathrm{~K}$. In the first stage, the mass loss is approximately $10.7 \%$, in the second step $2.8 \%$ and in the third one $1.8 \%$.

Figure 6 presents the results of the TGA analysis of titanium phosphate xerogel sample subjected to the hydrothermal treatment at $473 \mathrm{~K}$ (HTT-xero-200). As can be seen from the TG curve, the total mass loss was $15.4 \%$. The DTG plot shows five peaks occurring in the following temperature ranges: $320-421 \mathrm{~K}, 421-508 \mathrm{~K}, 698-734 \mathrm{~K}$, 734-842 K and 937-964 K. In these stages, the mass loss was $5.7 \% ; 3.3 \% ; 4.52 \%, 1.6 \%$ and $0.2 \%$, respectively.

The results of the TGA analysis of the titanium phosphate xerogel subjected to the hydrothermal treatment at $573 \mathrm{~K}$ (HTT-xero-300) are presented in Fig. 7. The TG curve shows that below $400 \mathrm{~K}$ the sample the mass loss did not change, so the sample did not contain physically adsorbed water. The latter can be associated with the minimal content of small pores, namely mesopores in this sample compared with the initial sample, for example (see

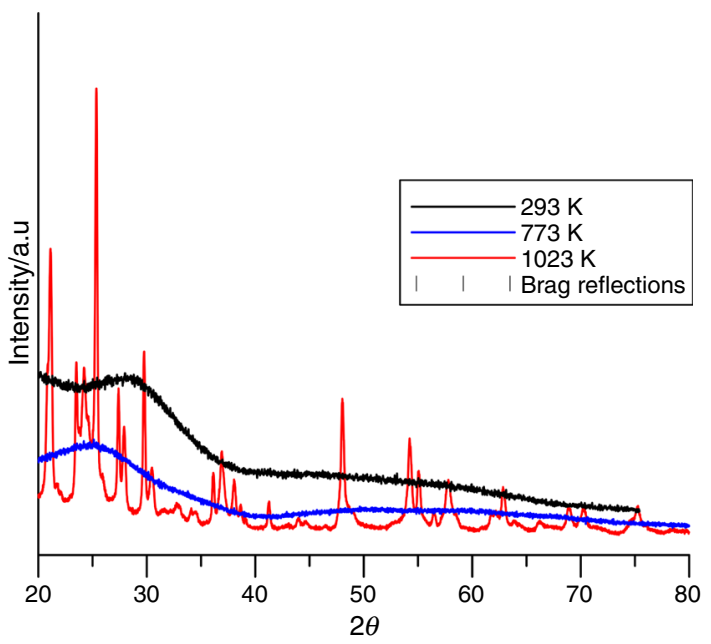

$00-039-0004$ | | | | | | | | | | $04-002-8296$ 04-014-7819

Fig. 8 The XRD pattern of the initial titanium phosphate samples: no heated and heated in 773 and $1023 \mathrm{~K}$

below, Table 3). The total mass loss of the sample heated at $1073 \mathrm{~K}$ was $7.96 \%$. This is statistically equal to 1.5 water molecules per $\mathrm{Ti}_{2}\left(\mathrm{PO}_{4}\right)_{2} \mathrm{O}\left(\mathrm{H}_{2} \mathrm{O}\right)$. One water molecule can be a result of structural decomposition of $\mathrm{Ti}_{2}(-$ $\left.\mathrm{PO}_{4}\right)_{2} \mathrm{O}\left(\mathrm{H}_{2} \mathrm{O}\right)$ and that of other phases present in the sample (Table 2).

The DTG plot shows one broad peak in the range $375-818 \mathrm{~K}$ and three relatively small ones with the

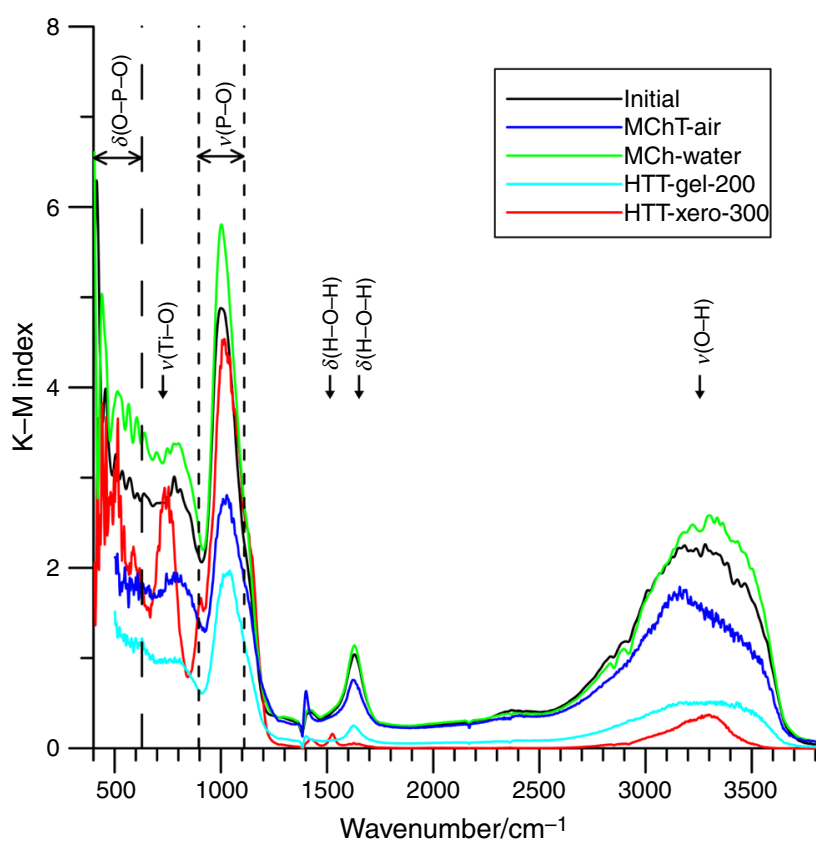

Fig. 9 The FTIR spectra of the titanium phosphate samples subjected to MChT and HTT 
maxima at 819, 961 and $1037 \mathrm{~K}$. The mass loss in the temperature ranges (process stages) was the following: $7.17 \%, 0.6 \%, 0.08 \%$, and $0.09 \%$. These changes indicate in the first stage (up to $829 \mathrm{~K}$ ) almost the whole water was released from the sample.

The FTIR spectra of the titanium phosphate samples: initial, MChT-air, MChT-water, HTT-gel-200 and HTTxero-300, are presented in Fig. 9. The observed bands were compared with the literature data for titanium phosphates [27, 28]. For the initial titanium phosphate sample, the broad band at $3280 \mathrm{~cm}^{-1}$ and the band at $1630 \mathrm{~cm}^{-1}$ correspond to the stretching and bending vibrations of hydroxyl groups [29]. The bands observed in the wave number range $383-628 \mathrm{~cm}^{-1}$ are attributed to the deformation modes, $\delta(\mathrm{O}-\mathrm{P}-\mathrm{O})$, whereas in the range $896-1110 \mathrm{~cm}^{-1}$ the stretching modes $v(\mathrm{P}-\mathrm{O})$ [27]. According to Bortun et al. [30], the band at $781 \mathrm{~cm}^{-1}$ may be assigned to the $\mathrm{TiOH}$ vibrations and $\mathrm{Ti}-\mathrm{O}$ bonds.

The bands in the wave number $1000-1050 \mathrm{~cm}^{-1}$ can be assigned to the Ti-O-P skeletal stretching vibrations $[31,32]$. The mechanochemical treatment in air of the titanium phosphate sample leads to a significant shift of the band at $3280 \mathrm{~cm}^{-1}$ to a lower wave number but that at $1028 \mathrm{~cm}^{-1}$ to a higher one. The mechanochemical treatment in water causes small changes in the band position.

The hydrothermal treatment of the xerogel sample at $573 \mathrm{~K}$ (HTT-xero-300) splits the band at $1630 \mathrm{~cm}^{-1}$ into 3 peaks at 1421,1525 , and $1626 \mathrm{~cm}^{-1}$. Additionally, the band at $781 \mathrm{~cm}^{-1}$ is shifted to $754 \mathrm{~cm}^{-1}$.

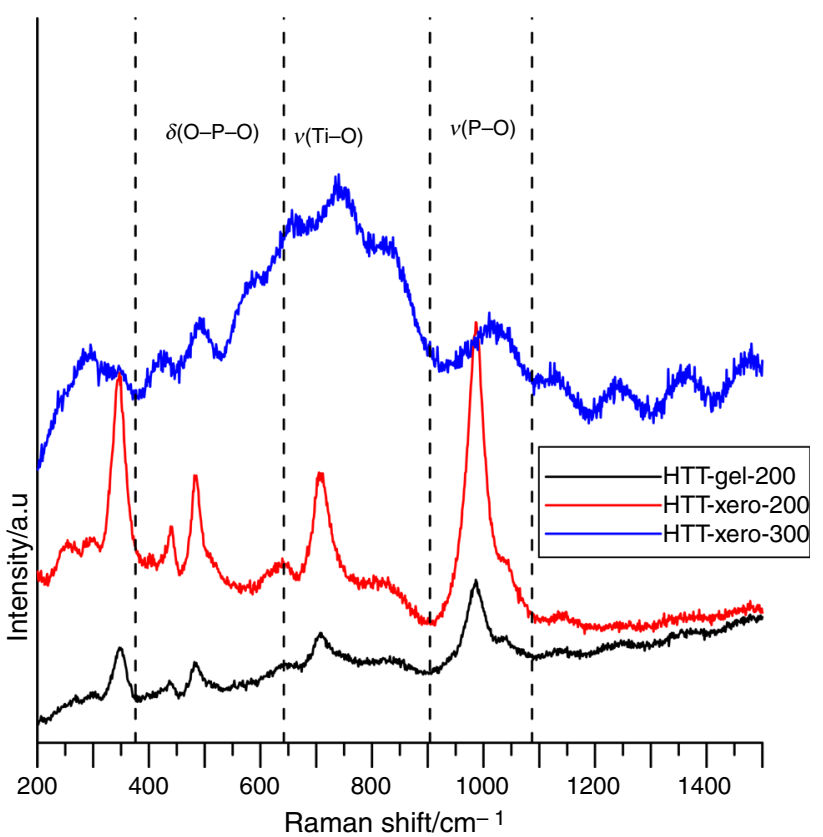

Fig. 10 The Raman spectra of the titanium phosphate samples subjected to HTT

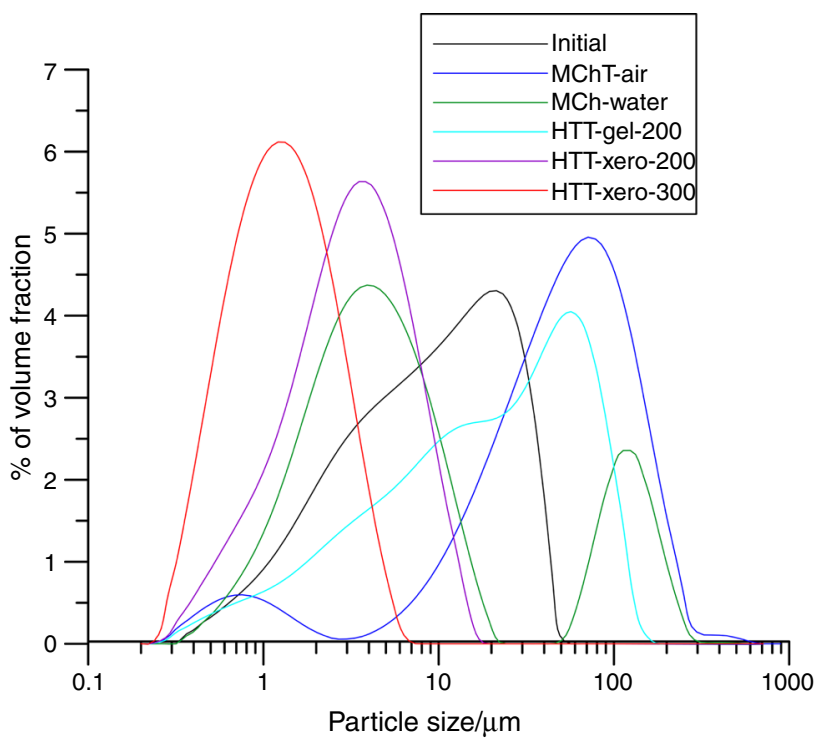

Fig. 11 Particle size distribution of the titanium phosphate samples

The Raman spectra of the titanium phosphate samples subjected to the hydrothermal treatment are shown in Fig. 10. The Raman bands for titanium phosphates have been reported in the literature [26, 27]. According to these data in Fig. 10, one can see the bands that could be assigned to the $\delta(\mathrm{O}-\mathrm{P}-\mathrm{O})$ deformation modes of $\mathrm{O}-\mathrm{P}-\mathrm{O}$ in the wave number range $376-642 \mathrm{~cm}^{-1}$, the stretching modes of $\mathrm{P}-\mathrm{O}$ in the range $904-1087 \mathrm{~cm}^{-1}$ and the stretching modes of Ti-O at $681 \mathrm{~cm}^{-1}$.

The particle size distribution of the titanium phosphate samples is presented in Fig. 11. The values of the particle diameters $[d(0.1) ; d(0.5)$ and $d(0.9)]$ that characterize the particle size distribution are collected in Table 4. The particle diameter of the initial phosphate sample falls between 0.35 and $56 \mu \mathrm{m}$ [the diameters characteristic of the distribution are $d(0.1)=1.8 \mu \mathrm{m}, d(0.5)=9.7 \mu \mathrm{m}$ and $d(0.9)=30.5 \mu \mathrm{m}]$. The comparison of particle size with the crystal size determined using the Scherer method indicates that particles of titanium phosphate are aggregates of crystal titanium phosphate. The particle distribution of this sample is broad, and its shape suggests that it is bimodal. The mechanochemical treatment of titanium phosphate in the planetary ball mill leads to aggregation of particles in the sample, and the characteristic diameter $d(0.9)$ is larger. The particle distribution is expanded to larger diameters. This effect is larger for the samples mechanochemically treated in air. The presence of larger diameter particles in the suspension makes particle size distribution measurements difficult due to aggregation during experiment that can be seen in the values of standard deviation of particle diameters in Table 4. The particle distribution of this sample, Fig. 11, is bimodal. The same effects were observed for the gel sample of titanium 
Table 4 The values of characteristic diameters $[d(0.1)$; $d(0.5)$ and $d(0.9)]$ of differently treated titanium phosphate samples

\begin{tabular}{lcccccc}
\hline$D / \mu \mathrm{m}$ & Initial & \multicolumn{1}{c}{ MChT-air } & MChT-water & HTT-gel-200 & HTT-xero-200 & HTT-xero-300 \\
\hline$d(0.1)$ & $1.8 \pm 0.1$ & $9.3 \pm 4.5$ & $1.5 \pm 0.1$ & $2.4 \pm 0.6$ & $1.0 \pm 0.1$ & $0.54 \pm 0.01$ \\
$d(0.5)$ & $9.7 \pm 0.1$ & $57.2 \pm 15.0$ & $5.2 \pm 0.4$ & $26.2 \pm 14.4$ & $3.4 \pm 0.1$ & $1.32 \pm 0.01$ \\
$d(0.9)$ & $30.5 \pm 0.6$ & $146.7 \pm 34.7$ & $120.2 \pm 19.4$ & $76.2 \pm 14.5$ & $8.5 \pm 0.3$ & $3.19 \pm 0.11$ \\
\hline
\end{tabular}

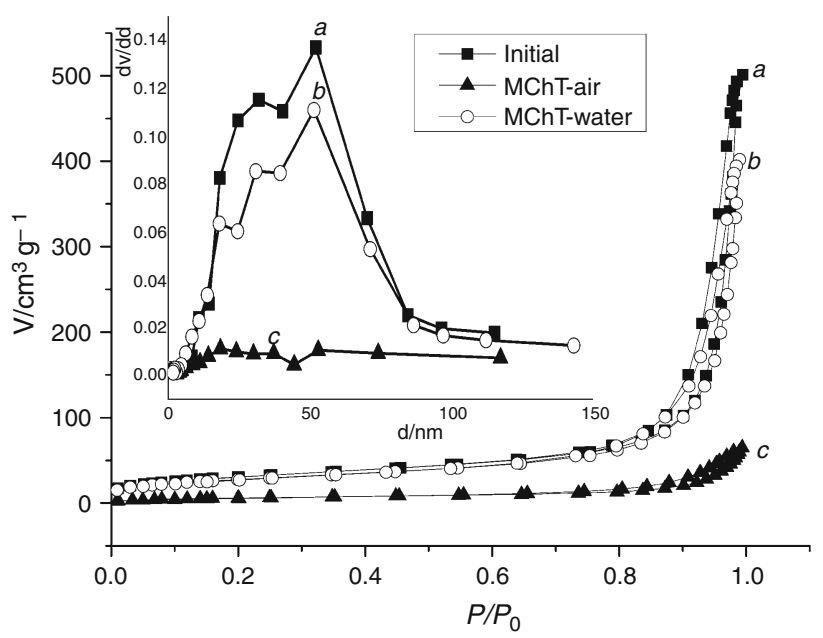

Fig. 12 Adsorption/desorption of $\mathrm{N}_{2}$ and pore size distribution in the initial titanium phosphate sample and MChT ones

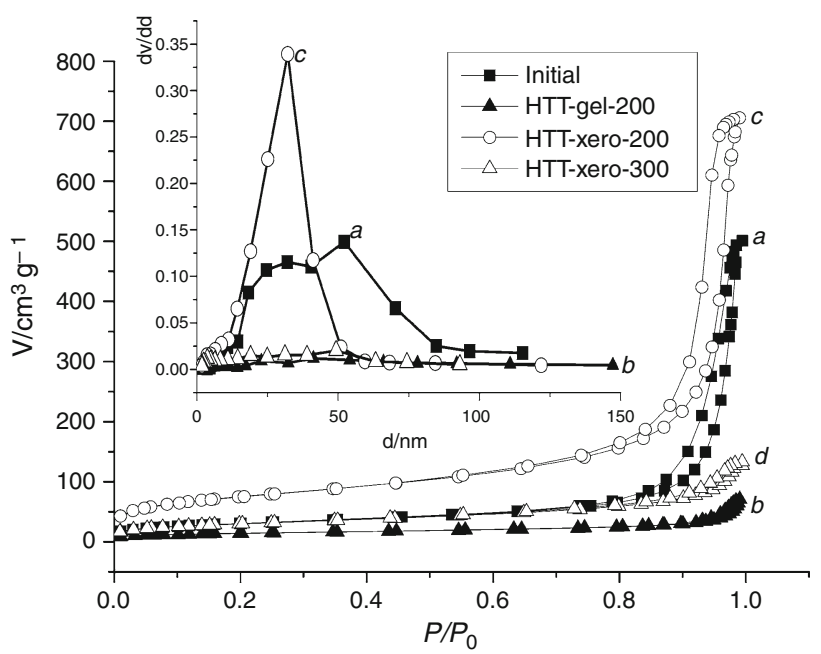

Fig. 13 Adsorption/desorption of $\mathrm{N}_{2}$ and pore size distribution in the initial titanium phosphate samples and the HTT ones phosphate subjected to the hydrothermal treatment. The hydrothermal treatment of the titanium phosphate xerogel allows to obtain a sample with narrow particle distribution, e.g., for HTT-xero-300 the characteristic diameters are $d(0.1)=0.54 \mu \mathrm{m}, d(0.5)=1.32 \mu \mathrm{m}$ and $d(0.9)=3,19 \mu \mathrm{m}$.

\section{Porous structure}

The nitrogen adsorption/desorption isotherms for all titanium phosphate samples are presented in Figs. 12, 13. As one can see the initial TiP sample is meso-macroporous. The shape of isotherms for this sample relates to type IV with the hysteresis loop of H1 type according to the IUPAC classification. Partial destruction of porous structure takes place during MChT: the specific surface area and the pore volume decrease (Table 5). Particularly, significant changes occur during dry milling which can be seen in Fig. 12: The isotherm (curve $c$ ) has a shape characteristic of type IV with a weakly expressed hysteresis of a region of large values $p / p_{0}$ which corresponds to the filling of the largest mesopores.

PSD showing distribution of mesopore sizes $d_{\text {me }}$ is practically unchanged after wet milling: Two maxima about 31-32 and 51-52 $\mathrm{nm}$ are present on the PSD curves of the initial sample and the samples milled in water (Fig. 13). At the same time, the PSD curve for the dry milled sample (MChT-air) is diffused and situated very low, i.e., mesoporous structure becomes less uniform.

On the contrary, HTT leads to the increase in total porosity $V_{\Sigma}$ (to $2.3 \mathrm{~cm}^{3} \mathrm{~g}^{-1}$ ) and its macroporous fraction. The sample modified at $473 \mathrm{~K}$ in the form of xerogel has a maximal value of the specific surface area (namely, $268 \mathrm{~m}^{2} \mathrm{~g}^{-1}$ that is more than twice the value of the specific surface area for the initial sample) and the volume of
Table 5 The parameters of porous structure of the titanium phosphate samples

\begin{tabular}{lllllll}
\hline No. & Sample & $S_{\mathrm{BET}} / \mathrm{m}^{2} \mathrm{~g}^{-1}$ & $V_{\Sigma} / \mathrm{cm}^{3} \mathrm{~g}^{-1}$ & $V_{\mathrm{me}} / \mathrm{cm}^{3} \mathrm{~g}^{-1}$ & $V_{\mathrm{ma}} / \mathrm{cm}^{3} \mathrm{~g}^{-1}$ & $d_{\mathrm{me}} / \mathrm{nm}$ \\
\hline 1 & Initial & 109 & 1.60 & 1.35 & 0.25 & $32 ; 52$ \\
2 & MChT-air & 22 & - & 0.10 & - & 19 \\
3 & MChT-water & 98 & 0.95 & 0.62 & 0.33 & $31 ; 51$ \\
4 & HTT-gel-200 & 51 & 2.30 & 0.10 & 2.20 & - \\
5 & HTT-xero-200 & 268 & 1.90 & 1.03 & 0.87 & 32 \\
6 & HTT-xero-300 & 107 & 1.72 & 0.19 & 1.53 & - \\
\hline
\end{tabular}


mesopores $\mathrm{V}_{\text {me }}$ (about $1 \mathrm{~cm}^{3} \mathrm{~g}^{-1}$ ) which can be seen in Fig. 13 and Table 5.

This sample (HTT-xero-200) possesses the most uniform porous structure which is confirmed by the curves of PSD (Fig. 13). However, the isotherms obtained for the samples modified at $473 \mathrm{~K}$ in the form of gel (HTT-gel200) and at $573 \mathrm{~K}$ in the form of xerogel (HTT-xero-300) can be attributed to type IV, although they do not contain hysteresis (Fig. 13). Nevertheless, calculations from the isotherms have shown that these samples contain large mesopores (Table 5). In general, increase in fraction of macropores is observed. The latter occurs due to transformation of the main part of mesopores into macropores. The parameters of porous structure for all samples are listed in Table 5.

\section{Conclusions}

The mechanochemical treatment of the xerogel titanium phosphate sample in air leads to aggregation of particles resulting in the decrease in the specific surface area, the pore volume and increase of the particle diameter. The effect of mechanochemical treatment of this sample in the water environment causes a smaller decrease in the specific surface area compared to the air-treated sample and results in the bimodal distribution of particle sizes (with one fraction of smaller particles and the second fraction with a larger diameter compared to the initial sample). The disadvantage of the mechanochemical treatment is contamination of the product by mechanical pulp of ball mill.

The hydrothermal treatment of the xerogel sample of titanium phosphate at $473 \mathrm{~K}$ allows to prepare the crystal product TiP with the specific surface area larger than that of the initial sample, and the particle size distribution is monomodal. The mixture of titanium oxide phosphate hydrate, titanium oxide phosphate and anatase is the product of such treatment. The HTT at $573 \mathrm{~K}$ of xerogel gives a similar product with a smaller specific surface area than that of the previous one, but the particle size distribution is narrower. Besides, all modified samples do not contain micropores and have bimodal meso-macroporous structure. Such samples are most required in adsorption and catalytic processes.

Open Access This article is distributed under the terms of the Creative Commons Attribution 4.0 International License (http://creative commons.org/licenses/by/4.0/), which permits unrestricted use, distribution, and reproduction in any medium, provided you give appropriate credit to the original author(s) and the source, provide a link to the Creative Commons license, and indicate if changes were made.

\section{References}

1. Ludmány A, Kurek SS, Stokłosa A, Wilczynski G, Wójtowicz A, Zajecki J. Amorphous titanium hydrogenphosphate-an inorganic sorbent and a catalyst. Appl Catal A. 2004;267:149-56.

2. Mu N. Inorganic and composite ion exchange materials and their applications. Ion Exch Lett. 2009;2:1-14.

3. Corma A. Solid acid catalysts. Curr Opin Solid State Mater Sci. 1997;2:63-75.

4. Xi M, Wu L, Li J, Li X. Hierarchical flower-like titanium phosphate derived from $\mathrm{H}$-titanate nanotubes for photocatalysis. J Mater Sci. 2015;50:7293-302.

5. Paul M, Pal N, Rana BS, Sinha AK, Bhaumik A. New mesoporous titanium-phosphorus mixed oxides having bifunctional catalytic activity. Catal Commun. 2009;10:2041-5.

6. Alberti G, Casciola M. Solid state protonic conductors, present main applications and future//. Solid State Ionics. 2001;145:3-16.

7. Clearfield A. Inorganic ion exchanger materials. Boca Raton: CRC Press; 1982. p. 304.

8. Lin R, Ding Y. A review on the synthesis and applications of mesostructured transition metal phosphates. Materials. 2013;6:217-43.

9. Dutta A, Patra AK, Dutta S, Saha B, Bhaumik A. Hierarchically porous titanium phosphate nanoparticles: an efficient solid acid catalyst for microwave assisted conversion of biomass and carbohydrates into 5-hydroxymethylfurfural. J Mater Chem. 2012;22:14094-100.

10. Fei H, Zhou X, Zhou H, Shen Z, Sun P, Yuan Z, Chen T. Facile template-free synthesis of meso-macroporous titanium phosphate with hierarchical pore structure. Microporous Mesoporous Mater. 2007;100:139-45.

11. Jones DJ, Aptel G, Brandhorst M, Jacquin M, Jimenez-Jimenez J, Jimenez-Lopez A, Maireles-Torres P, Piwonski I, RodriguezCastellon E, Zajac J, Rozière J. High surface area mesoporous titanium phosphate: synthesis and surface acidity determination. J Mater Chem. 2000;10:1957-63.

12. Ren TZ, Yuan ZY, Azioune A, Pireaux JJ, Su BL. Tailoring the porous hierarchy of titanium phosphates. Langmuir. 2006;22:3886-94.

13. Janusz W, Khalameida S, Sydorchuk V, Skwarek E, Zazhigalov V, Skubiszewska-Zięba J, Leboda R. Some properties of milled vanadium phosphate. Adsorption. 2010;16:333-41.

14. Khalameida S, Sydorchuk V, Skubiszewska-Zięba J, Charmas B. Hydrothermal, microwave and mechanochemical modification of amorphous zirconium phosphate structure. J Therm Anal Calorim. 2017;128:795-806.

15. Leboda R, Charmas B, Sydorchuk VV. Physicochemical and technological aspects of hydrothermal modification of complex sorbents and catalysts. I. Modification of porous and crystalline structures. Adsorp Sci Technol. 1997;15:189-214.

16. Zaitseva GO, Strelko VV, Yakovlev VI. Mesoporous spherically granulated titanium phosphates synthesized from titanyl sulfate. Chem Phys Technol Surf. 2003;9:156-61.

17. Zaitseva AA, Kanibolotsky VA, Strelko VV. New spherically granulated inorganic ion exchangers on the basis of titanium phosphate. In: Loureiro JM, Kartel MT, editors. Combined and hybrid adsorbents. Berlin: Springer; 2006. p. 99-104.

18. Przepiera A, Przepiera K, Plaska J. Preparation of titanium(IV) phosphates. Pol J Appl Chem. 2008;LII(1-2):91-100.

19. Reynolds HS, Bhargava S. Frank antolasic structural investigation of titanyl sulfate dihydrate and intermediates formed during thermal decomposition. In: Engineering our future: are we up to the challenge? 27-30 September 2009. Barton: Engineers Australia; 2009. p. 1779-88. 
20. Fang J, Shi F, Bu J, Ding J, Xu S, Bao J, Ma Y, Jiang Z, Zhang W, Gao Ch, Huang W. One-step synthesis of bifunctional $\mathrm{TiO}_{2}$ catalysts and their photocatalytic activity. J Phys Chem C. 2010;114:7940-8.

21. Bereznitski Y, Jaroniec M, Bortun AI, Poojary DM, Clearfield A. Surface and structural properties of novel titanium phosphates. J Colloid Interface Sci. 1997;191:442-8.

22. Takahashi H, Oi T, Hosoe M. Characterization of semicrystalline titanium(IV) phosphates and their selectivity of cations and lithium isotopes. J Mater Chem. 2002;12:2513-8.

23. Korosi L, Papp S, Dekany I. A layered titanium phosphate $\mathrm{Ti}_{2-}$ $\mathrm{O}_{3}\left(\mathrm{H}_{2} \mathrm{PO}_{4}\right)_{2} \quad 2 \mathrm{H}_{2} \mathrm{O}$ with rectangular morphology: synthesis, structure, and cysteamine intercalation. Chem Mater. 2010;22:4356-63.

24. Bortun AI, Bortun L, Clearfield A, Villa-Garcia MA, Garcia JR, Rodriguez J. Synthesis and characterization of a novel layered titanium phosphate. J Mater Res. 1996;11:2490-8.

25. Maslova MV, Rusanova D, Naydenov V, Antzutkin ON, Gerasimova LG. Extended study on the synthesis of amorphous titanium phosphates with tailored sorption properties. J NonCryst Solids. 2012;358:2943-50.

26. Paunovic P, Grozdanov A, Makreski P, Fidancheevska E. Preparation of nano-crystaline $\mathrm{TiO}_{2}$ by sol-gel method using titanium tetraisopropoxide (TTIP). Adv Nat Sci Theory Appl. 2012;1:133-42.

27. Stanghellini PL, Boccaleri E, Diana E, Alberti G, Vivani R. Vibrational study of some layered structures based on titanium and zirconium phosphates. Inorg Chem. 2004;43:5698-703.

28. Benmokhtar S, El Jazoulia A, Chaminade JP, Gravereau P, Menetrier M, Bouree F. New process of preparation, structure, and physicochemical investigations of the new titanyl phosphate $\mathrm{Ti}_{2} \mathrm{O}\left(\mathrm{H}_{2} \mathrm{O}\right)\left(\mathrm{PO}_{4}\right)_{2}$. J Solid State Chem. 2007;180:2713-22.

29. Lin L, Lin W, Xie JL, Zhu YX, Zhao BY, Xie YC. Photocatalytic properties of phosphor-doped titania nanoparticles. Appl Catal B. 2007;75:52-8.

30. Bortun AI, Khainakov A, Bortun LN, Poojary DM, Rodrıguez J, Garcia JR, Clearfield A. Synthesis and characterization of two novel fibrous titanium phosphates $\mathrm{Ti}_{2} \mathrm{O}\left(\mathrm{PO}_{4}\right)_{2} 2 \mathrm{H}_{2} \mathrm{O}$. Chem Mater. 1997;9:1805-11.

31. Samantaray SK, Parida KM. Review effect of anions on the textural and catalytic activity of titania. $\mathbf{J}$ Mater Sci. 2003;38:1835.

32. Pan C, Yuan S, Zhang W. A neutral templating route to mesoporous titanium phosphate molecular sieves with enhanced thermal stability. Appl Catal A. 2006;312:186-93. 